Our house accommodates thirty members. (Once in the old house we had fifty, but found that this number was unwieldy and that the club lost its home-like atmosphere.) Eight members occupy double and the rest single rooms. We had four double rooms in case there should be sisters or friends who might wish to room together.

I think we have one advantage which a club for nurses or for any set of people of the same occupation can never have: that is, that we have all sorts and conditions of people,-I mean, people of all sorts and conditions of occupation. This must, I think, tend to broaden the interests, which, after all, is what makes for rcal living. N'est ce pas?

\title{
HOW TRAINED NURSING BEGAN IN AMERICA
}

[In connection with the Congress papers which show the heights to which trained nursing has attained, histories of the pioneer schools are of especial interest at this time. Later we shall give a sketch of the early work of the Boston Training-School connected with the Massachusetts General Hospital, prepared by Mrs. Curtis and Miss Denny, members of the original Board of Managers.—ED.]

\section{AT THE NEW ENGLAND HOSPITAL BY LINDA RICHARDS}

On the first day of September, 1872, the doors of the New England Hospital (then on Florence Street, Boston, Mass.) opened to admit a class of five nurses entering the school that day organized. Its organizer and originator was Susan Dimock, M.D., who after graduating from a medical school in America had spent four years in study in Germany. The larger part of the last year of the four had been spent in Kaiserswerth, and she had taken special pains to learn the system of nursing under the deaconesses there. As there were no graduate nurses in America at that time, Dr. Dimock, then a young woman of twenty-eight years, assumed the charge of the school as well as that of the hospital. The hospital had a capacity of thirty beds. Two weeks after the opening of the school the patients were moved to the new hospital, which accommodated seventy-two patients. These were medical, "'rgical, obstetrical, and sick children. The course was one year. Three $m^{r} n$ ths were devoted to medical, three to surgical, three to obstetrical nursing, and one to the care of sick children. Two months were spent on night duty. There were in the hospital two experienced nurses, but these were not allowed to teach the pupils, as Dr. Dimock, a progressive woman, believed in new 


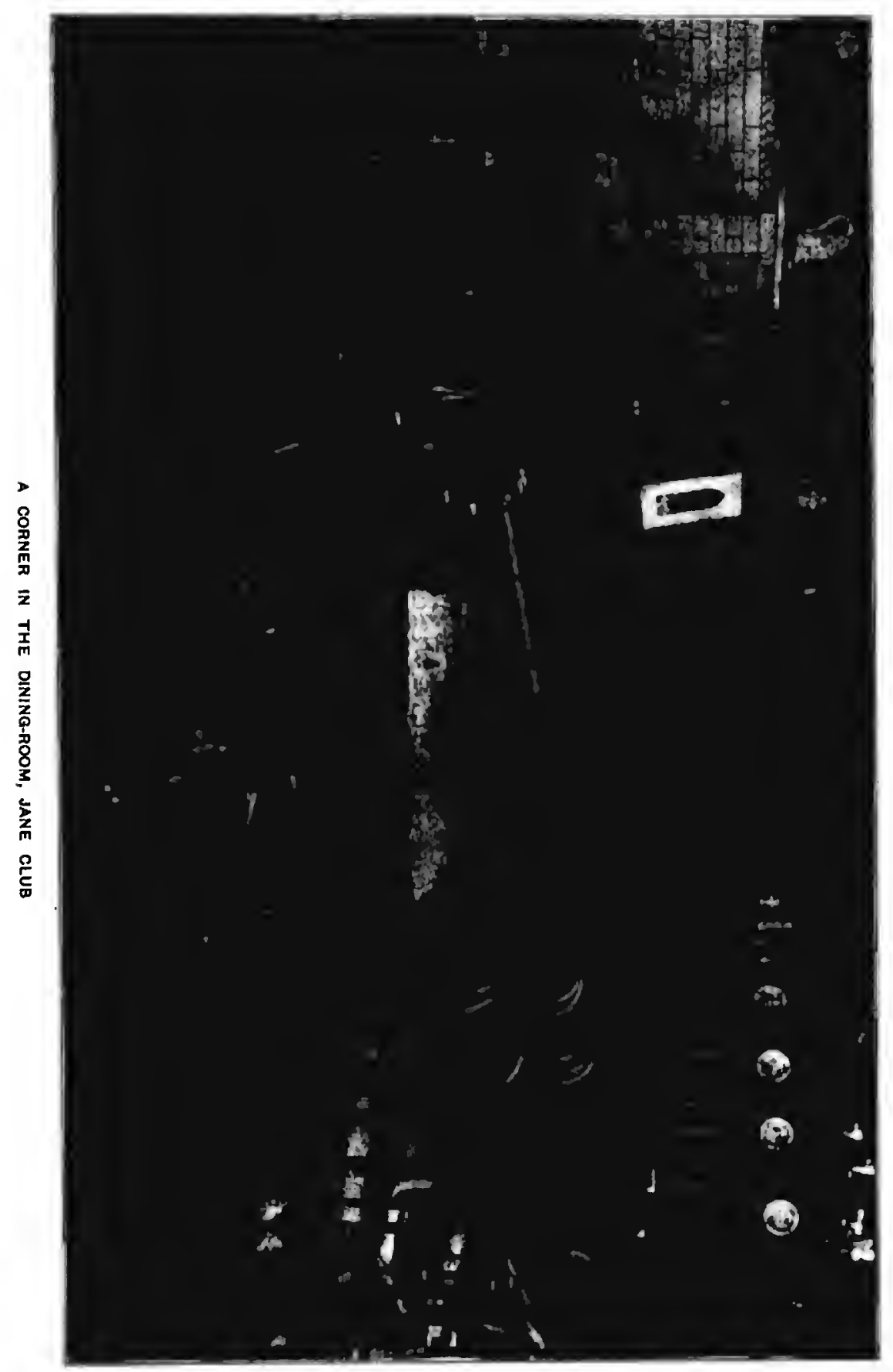


methods. So each nurse was installed in charge of her ward with someone from outside to help her. No class-work was required. Lectures were given during the winter months, but notes were not required. At the end of the year diplomas were awarded, only one being given on September 1, 1873. Other nurses had time to make up for sickness. At the end of the first six months four additional nurses were admitted to the school, these last four making a class by themselves. The commencement of the second year found one of the graduate nurses installed as head nurse and instructor of nurses, and class work was commenced. The school term was lengthened to sixteen months. When the second class graduated a second head nurse was retained, thus giving one to the obstetrical work and one for the general work. These nurses were responsible to the superintendent of the hospital. When the school was five years old it had a graduate superintendent of nurses, with two head nurse graduates, and a course of eighteen months, the nurses serving one month in the diet kitchen at the hospital and one in district work in the city, this work in connection with the dispensary of the New England Hospital on Fayette Street, Boston. The school now had grown to fifteen pupils, two graduate head nurses, and a superintendent of trainingschool. Soon after this a small cottage was purchased not far from the hospital and was fitted up for a contagious ward, and nurses had training in contagious cases excepting diphtheria and small-pox. The school was increased to meet the demand. In 1890 a new maternity building was erected and the old one remodelled into a home for nurses, and the school again added to its members till it numbered twenty pupils. In 1893 the school term was lengthened to two years, and in 1901 to three years, and in 1899 a new and very complete surgical building was added, and this made a demand for additional nurses, so that to-day the number is about twenty-five, exclusive of graduate head nurses.

\section{HISTORY OF THE REFORM IN NURSING IN BELLEVUE HOSPITAL \\ COXPILED BY L. L. DOCK}

REPORT OF THE HOSPITAL VISITING COMMITTEE OF THE STATE CHARITIES AID ASSOCIATION.

December 23, 1872.

The association began its work in New York City through its Local Visiting Committee for Bellevue Hospital in 1871. . . . The members of the Bellevue Association could not patiently witness the ignorance and brutality which daily fell under their eyes, and they applied to the Commissioners of Charities for permission to establish a school for nurses at 
Bellevue. The Commissioners replied to their appeal by referring the subject to the Medical Board for decision. Dr. Gill Wylie, formerly one of the resident staff of Bellerue and now a member of the Hospital Committee of the State Charities Aid, volunteered to risit England and the Continent at his own expense and study the system of nursing as practised in the schools and hospitals of those countries. After an absence of three months, exclusively devoted to this work, he returned and made a most interesting report to the association, from which we quote as follows :

"The name of Florence Nightingale is as familiar to Americans as to Englishmen. We connect it with the memories of the Crimean War and with hospitals elsewhere, and yet how few of us know anything of her real work. After the Crimean War her grateful countrymen subscribed a large sum of money at a public meeting as a memorial of her services, and at her request this sum was devoted to the foundation of an 'Institution for the Training, Sustenance, and Protection of Nurses and Hospital Attendants.'

“This institution was established at St. Thomas's Hospital, London, and from time to time during the last twelve years women trained in this school have been sent to all parts of England and her colonies as superintendents, matrons, and training-nurses in hospitals. The main points of the system have been adopted in nearly all the hospitals of London and the other large towns in England, while here, at this late date, the subject is only just beginning to inspire interest.

"On the Thames Embankment the eight pavilions of St. Thomas's Hospital rear their stately façades for a quarter of a mile in face of the Houses of Parliament and Westminster Abbey. . . . The building which has been erected for the accommodation of the probationers, called the ' Nightingale Home,' adjoins the house of the matron, Mrs. Wardroper. It is entered from the main corridor of the hospital, and contains on the ground floor a capacious dining-room, with adjoining room for the sister in charge. Above these are four floors of bedrooms, affording a separate room for each of the thirty-five probationers, bath-rooms, and a dayroom for convalescents.

"Mrs. Wardroper has been matron of this hospital of six hundred beds for eighteen years. She is also lady superintendent of the Nightingale Training-School for Nurses and fulfils these varied duties in the most satisfactory manner.

"Their arrangements for the nursing staff are as follows:

"There are in all sixteen hospital sisters or head nurses, one of whom acts as superintendent of night nurses and one as matron's assistant. There are fifty-four nurses and three nurse-maids; to five of the 
head nurses are assigned two wards each; to seven, one each; and there is one sister for the infectious block.

"The probationers are employed as assistant nurses under the immediate direction of the head nurses. They pass, during the year's training, successively through all the different wards, and there are to about thirty patients one head nurse, one day nurse, one night nurse, two probationerassistants, and one ward maid; whereas at Bellevue to the same number of patients there is one nurse without an assistant, one-fifth of the time a night nurse, and one ward maid, if the ten days' prisoners convicted for drunkenness who do the cleaning can receive such a title.

"As to the instruction given outside the wards, a few lectures are delivered each season on principles of medicine, surgical subjects, chemistry, and the properties of air and light. While these lectures are being delivered the probationers take notes and afterwards write out the lectures. The subjects are treated in the simplest style. . . .

"In answer to a letter which I addressed to Miss Nightingale I received the following reply:

" 'Londox, September 18, 1871.

" 'SiR: First, let me explain that your letter from Paris of August 26 was, most unfortunately, not forwarded to me till the day after that on which you proposed to leave England.

" "When it reached me I was overwhelmed with business and illness. (I should, perhaps, add that my medical advisers have warned me that if I have business interviews of more than half an hour it is at the risk of my life.) Add to this, at the moment of receiving your letter my niece, who was to me like my own child, Sir Henry Verney's only daughter, had been but two hours dead. (She would have done a great work in God's service had she lived.)

" ' But I have been so little used to regarding my own life or the lives of those dearest to me as preventing God's business, that I would have seen you, as you desired, had it not, as I have explained, been, alas, too late. Excuse me for giving these personal details; I wish to show that there is no indifference on my part; that if I could have been of service I would.

"'I wish your association God-speed with all my heart and soul in their task of reform, and will gladly, if $I$ can, answer any questions you may think it worth while to ask.

" "You say, "The great difficulty will be to define the instructions, the duties, and the position of the nurses in distinction from those of medical men, and you are anxious to get my views in relation to this subject."

"' 'Is this a difficulty? A nurse is not a medical man; nor is she a medical woman. (Most carefully do we, in our training, avoid the confusion, both practically and theoretically, of letting women suppose that nursing duties and medical duties run into or overlap each other; 80 much so that although we have often been asked to allow ladies intending to be "doctors" to come in as nurses to St. Thomas's Hospital in order to "pick up"-so they phrased it-professional medical knowledge, we have never consented to admit such applications, in order to avoid even the semblance of encouraging such gross ignorance and dabbling in matters of life and death as this implies.) 
" "Nurses are not " medical men." On the contrary, the nurses are there, and solely there, to carry out the orders of the medical and surgical staff, including, of course, the whole practice of cleanliness, fresh air, diet, etc. The whole organization of discipline to which the nurses must be subjected is to carry out intelligently and faithfully such orders and such duties as constitute the whole practice of nursing. They are in no sense medical men. Their duties can never clash with medical duties. Their whole training is to enable them to understand how best to carry out medical and surgical orders, including, as above, the whole art of cleanliness, ventilation, food, etc., etc., and the reason why this is to be done this way and not that way.

" And for this very purpose-that is, in order that they may be competent to execute medical directions, to be nurses and not doctors-they must be, for discipline and internal management, entirely under a woman, a trained superintendent, whose whole business is to see that the nursing duties are performed according to this standard. For this purpose may I say:

" ' l. That the nursing of hospitals, including the carrying out of medical officers' orders, must be done to the satisfaction of the medical officers, whose orders regarding the sick are to be carried out. And we may depend upon it that the highly trained, intelligent nurse and cultivated, moral woman will do this better than the ignorant, stupid woman, for ignorance is always headstrong.

" 2. That all desired changes, reprimands, etc., etc., in the nursing and for the nurses should be referred by medical officers to the superintendent.

"That rules which make the matron (superintendent) and nurses responsible to the house surgeons or medical or surgical staffs, except in the sense of carrying out current medical orders above insisted upon, are always found fatal to nursing discipline. That if the medical officers have fault to find, it is bad policy for them to reprimand the nurses themselves. The medical staff must carry all considerable complaints to the matron; the current complaints, as, for instance, that a patient has been neglected or an order mistaken, to the ward sister or the head nurse, who must always accompany the medical officer on his visits, receive his orders, and be responsible for their being carried out.

"3. All discipline must be under the matron (superintendent) and ward sisters, or otherwise nursing becomes impossible.

" 'And here I should add that, unless there is, so to speak, a hierarchy of women, as thus-

$$
\begin{aligned}
& \text { Matron or Superintendent, } \\
& \text { Sisters or Head Nurses, } \\
& \text { Assistant and Night Nurses, } \\
& \text { Ward Maids or Scrubbers, }
\end{aligned}
$$

or whatever other grades are, locally, considered more appropriate, discipline becomes impossible.

" 'In this hierarchy the higher grade ought always to know the duties of the lower better than the lower grade does itself. And so on to the head. Otherwise, how will they be able to train? (Moral influence alone will not make a good trainer.)

" I will now mention, as an instance, that the very day I received your first message, through Mrs. Wardroper, I received a letter from a well-known German physician strikingly exemplifying what we have been saying as to the necessity of hospital nurses being in no way under the medical staff as to discipline, but under a matron or superintendent of their own, who is responsible for the carrying out of medical orders. 
“' You are, doubtless, aware that this is by no means the custom in Germany. There the ward nurse is immediately, and for everything, under the ward doctor. And this led to consequences so disastrous that, going to the opposite extreme, Kaiserswerth and other German Protestant Deaconess Institutions were formed, where the chaplain and the Vorsteherin (female superintendent) were, virtually, masters of the hospital, which is, of course, absurd.

" My friend, then, who has heen for forty years medical officer of one of the largest hospitals in Germany, wrote to me that he had succeeded in placing a matron over his nurses; then, that after one and a half years she had been so persecuted that she had been compelled to resign; then, that he had remained another year trying to have her replaced; lastly, that failing, he had himself resigned his post of forty years, helieving that he could do hetter work for this reform outside the hospital than in it.

" 'It seems extraordinary that this first essential, viz., that women should be, in matters of discipline, under a woman, should need to be advocated at all. But so it is.

" ' And I can add my testimony, as regards another vast hospital in Germany, to the abominable effects of nurses being directly responsible, not to a matron, but to the economic staff and medical staff of their hospital. And I am told on the highest authority that since my time things have only got worse.

"' But I will not take up your time and my own with more general remarks, which may not prove, after all, applicable to your special case. . . .

" Again begging you to command me if $I$ can be of any use for your great purpose, to which I wish every success and ever-increasing progress, pray believe me, sir,

"' Ever your faithful servant, " Floressce Nightugante." "

Dr. Wylie risited all the large hospitals of London, the Royal Infirmary at Liverpool, and also the hospitals of Paris and Vienna, all of which he described with more or less detail in the report to the Hospital Committee, which then continues as follows: No action having been taken by the Medical Board of Bellevue in answer to the communication in the spring at the meeting of the Bellevue Hospital Association, in September, 1872, it was resolved to refer the subject of the establishment of a training-school for nurses to the Hospital Committee of the State Charities Aid Association. This committee, after a thoughtful study of the subject, prepared a scheme for the establishment of a school at Bellerue adapted to the wants of that hospital, but sufficiently comprehensive to be extended on a large scale at a future time. This scheme was presented to a committee of the Medical Board of Bellevue appointed for this object, composed of Dr. James R. Wood, chairman, Dr. Stephen Smith, Dr. Austin Flint, and Dr. Thomas M. Markoe. Three days after this committee presented the plan to the Medical Board, which passed a unanimous resolution of approval and sent it to the Commissioners of Charities. These gentlemen have conveyed to us a most cordial expression of their desire to carry out any well-considered plan for the benefit 
of the patients under their charge, and for this end they agree to our proposal to give up to us the nursing and control of six wards of Bellevue Hospital, subject to such conditions as will not conflict with the rules already established for the good government of the hospital.

In the plan offered for the establishment of the school at Bellevue we ask only for the control and nursing of six wards; more than this it would be impossible to attempt satisfactorily at first. In course of time we propose to benefit not only Bellevue, but all the public hospitals, and also to train nurses for the sick in private houses and for the work among the poor. As the work advances we hope to establish a college for the training of nurses which will receive a charter from the State and become a recognized institution of the country.* Branches of this college would be established in connection with hospitals devoted to particular diseases, such as the Woman's Hospital, etc., so that in course of time nurses trained for the treatment of special diseases will be as easily obtained as physicians. Connected with the college would be a "Home," whence they would be supplied with employment, and provision made for them when ill and disabled by labor or advanced years. The nurses when trained would receive a diploma or certificate, renewable at fixed periods. Thus the college would control the nurses during the stage of pupilage and protect the public from imposition by making known that a nurse whose diploma or certificate was not in due form had forfeited the confidence of the institution.

We would here offer our gratitude to the noble woman whose example has inspired our work, and who has sent us from her sick-bed invaluable advice and coöperation. We fervently trust that Miss Nightingale may long survive and may rejoice to learn that the work she had inspired in English-speaking women in this western world is bearing the same lifegiving fruit that she and her co-workers gathered among the sick and suffering beyond the Dardanelles.

The branch of the work of district or missionary nursing among the poor, described in Dr. Wylie's report, must appeal strongly to the sympathies of all benevolent hearts. . . .

In Liverpool, where this branch of work has been carried to the greatest perfection in England, it has been productive of the most satisfactory results, and it remains to be decided what arrangements will be best to adopt in this country, and whether the different dispensaries established throughout the city should form a part of the mission work already organized by the different churches. We propose to train the nurses, and leave it to those who know New York and its needs to decide how best to use them.

* The school was incorporated in 1874. 
The work before us is not an inexpensive one. It should not be regarded merely in the light of a work of benevolence, but as a system of education, calculated to benefit thousands in all ranks of life, and, like the quality of mercy, blessing him that gives and him that takes.

We require at present the sum of twenty thousand dollars.* A house must be had for the superintendent and nurses; not a mere lodging, but a comfortable home, where, after their daily labors, they may find relaxation and rest, free from the depressing influences of the hospital. Our head nurses, on whom will devolve the task of training the probationers, will be entitled to the high wages they would receive in private houses. To the probationers we shall give moderate wages, on a rising scale, in proportion to their usefulness and term of service.

It will be seen by Dr. Wylie's report that the nurses trained in England are chiefly recruited from the class of upper servants. In this country women of that class find plenty of employment at high wages; we propose, therefore, to offer the advantages of our school to women of a higher grade. In this country we have a large class of conscientious and laborious women whose education and early associations would lead them to aspire to some higher and more thoughtful labor than household service or work in shops, such as daughters and widows of clergymen, professional men, and farmers who have received the good education of our common schools and academies, and are dependent on their own exertions for support. An American woman, with such an education and with her heart in the work, could be trained to become the best nurse in the world, for the race has quick wit, perception, and strong powers of observation. Let her, in addition to these qualities, acquire the habit of obedience, and you have all the elements for making a good nurse.

There is an idea prevalent that among certain classes the work of nursing can best be done by persons who receive no pay, but simply a support from the order to which they belong - that the receipt of money gives the stigma of servility to the work. While we would not in any way depreciate the usefulness of the persons holding these views, we feel that the idea is an erroneous one; that such a rule shuts out a vast number whose services would be invaluable.

For the Committee on Hospitals,

Elizabeth C. Hobson, Chairman.

- Six weeks after the publication of this report the sum of twenty-three thousand dollars was contributed. 
THIRD ANNUAL REPORT OF THE MANAGERS OF THE TRAINING-SOHOOL, 1876.

In presenting their Third Annual Report the managers of the Training-School would claim that the experiment begun with many fears and misgivings in May, 1872, has proved a success, and that the hope they then ventured to express, of training respectable, intelligent women into educated, skilful nurses, has grown into a reality.

The first two years of the work may have seemed barren of result, and have tested the patience of the kind friends who furnished the funds for the establishment of the school, for, as the course of training required two years, it was impossible to graduate the first class of pupils until last May. The school opened with but five pupils. Applications for admission came slowly, or, rather, the applicants were many, but few among them were willing to give up two years to the acquisition of a profession, no matter how useful and lucrative that profession might be. This, one of the most serious of the early difficulties, no longer exists. As the story of the school spread through the country, the applications from women deliberately choosing the profession of a nurse as their lifework and anxious to learn it thoroughly are more numerous than we can accept.

There are now forty pupils in the school, with others engaged, waiting for the first vacancies, to enter.

In May, 1875, our first class of six nurses graduated, receiving a diploma signed by the Examining Diploma Committee of the Medical Board of Bellevue and by the Training-School Committee. Of these, the first fruits of our work, one is now matron of Roosevelt Hospital, one a head nurse at the Maternity Hospital, one is established for herself in private practice in New York, and three are temporarily reëngaged by the school and sent out by it to private cases.

The course during the year has been as follows: Eight lectures upon circulation, respiration, digestion, diseases of women, and care of children; four lectures on obstetrics ; ten on anatomy, physiology, and digestion; two on symptoms of disease and temperature; three on digestion; two on obstetrics; one on walking; one on hemorrhages; one on bedside manipulations.

Add to these a regular and most valuable course of lectures from the assistant superintendent on the various duties of a nurse, on urine, wounds, and eruptive and typhoid fevers.

The constant presence of respectable, intelligent women as nurses in the wards and the daily example of their lives is the best of sermons, teaching patience under suffering, touching sad, lonely hearts with a sense 


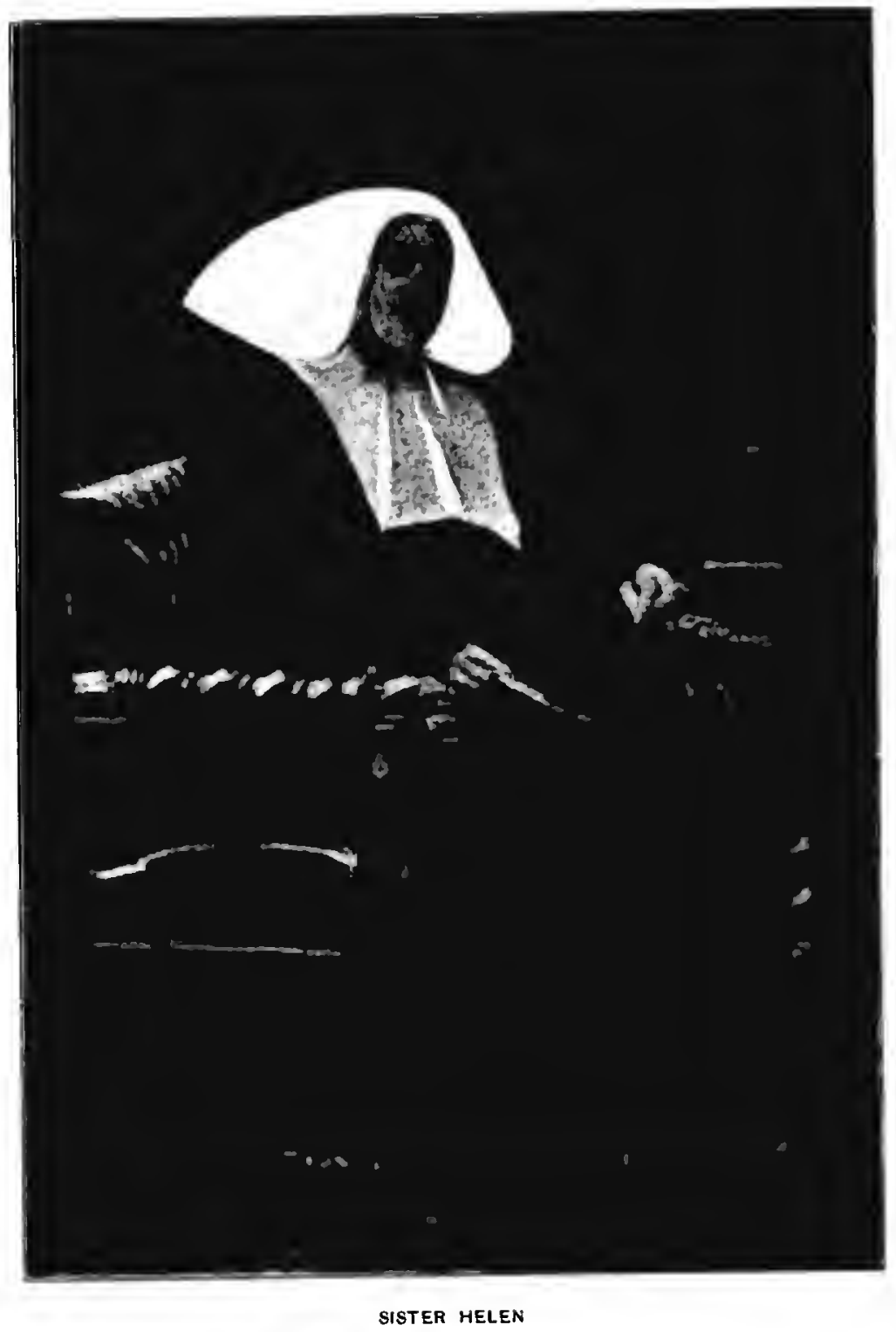

First Gujerintendent of the Training-Sehoml for Nurses of Bellevue Hospital, New York 
of sympathy, quelling angry disputes, silencing oaths and obscene talk, and extending its influence to the lowest and most degraded.

The account of the early days of the school as read at the twentyfifth anniversary of the establishment of trained nursing in this country, held at the Waldorf-Astoria on March 6, 1899, gives the following details of that pioneer work:

"Through the influence of the Honorable James Bowen, one of the Commissioners of the Board of Charities, a reluctant consent had been obtained from the board to allow us to nurse five wards at Bellevue, for which the committee was to defray all the expense beyond what was paid under the old system. A house was hired in March, 1873, in the vicinity of the hospital as a home for the nurses, and the committee engaged to take charge of the fire wards the first of May. Circulars were issued inviting pupils to apply, and search was made for head nurses and a lady superintendent. At the end of several weeks six pupils were with diffculty obtained, and one nurse engaged who claimed to have had nursing experience. No person qualified to take the position of superintendent, as Miss Nightingale had defined it, was to be found. It was close upon the first of May, and the committee was threatened with the prospect of failing to meet its engagements, thus fulfilling the prophecies of its opponents. A little anecdote here may not be inappropriate: A member of the committee in a despondent mood at this time expressed her anxiety to another, who replied, 'I have such faith in this work, and I have prayed so hard for it, that I shall have that superintendent's bed made, being sure that she will come to occupy it.' A few days later the despondent member was at her breakfast-table when a woman in the garb of a sister was announced. Her English accent betrayed her nationality as she explained that she had heard we were establishing a training-school for nurses in New York, and as she had had considerable experience in such work she had come to offer her services. The result of that visit was the engagement of Sister Helen, of the All Saints' Sisterhood in London, as superintendent.

"The school started its struggling, tentative work the first of May, 1873, amid a good deal of opposition, but it never wavered or faltered from its high ideals, and the principles accepted from Miss Nightingale have been faithfully followed, not only at Bellevue, but by all the schools subsequently founded, up to the present time.

"The principle which Miss Nightingale insisted upon as fundamental, and which excited the greatest opposition among hospital authorities, was that all nurses should in matters of discipline be under a woman, who should be responsible to the hospital authorities for the behavior of her subordinates and for the faithful performance of their duties. 
"This was such an innovation in hospital rule that it created great opposition at first in this country as well as in Europe, but following the advice of Miss Nightingale, the committee stood firm, carried its point, and as time passed on and the school extended until it controlled all the nursing in the hospital, the rule was accepted without a question, and as other schools were founded the superintendents carried these rules with them, until now no other system is in use in any hospitals in England or in civil hospitals in this country.

" At the expiration of the first year, the house staff, who had been friendly from the beginning, ventured to point out to their superiors the improved condition of the nursing service under the training-school, and gradually the eyes of these gentlemen were opened to the fact that their patients recovered sooner, and that the deaths after operation were less frequent than formerly.

"The superintendent, Sister Helen, accustomed to the management of a pauper hospital in England, was not daunted by the politics of Bellevue, and gradually during the second year the work assumed permanent shape and was extended to other wards. The applications from would-be pupils increased. The first pupils became head nurses and, at the end of the second year, the first class graduated.*

"In May, 1876, Sister Helen, having taught us how to go alone, returned to England, and the school was placed in charge of Miss Eliza Perkins, of Norwich, Conn.

"If the prayer was answered which sent the school its first superintendent, the Divine guidance certainly inspired the selection of the second. It would be impossible for anyone who was not associated with Miss Perkins during the years she was matron of the hospital and superintendent of the school to realize the value of her work and the qualities of her head and heart. She studied the character and abilities of her pupils, knew the position each woman was adapted to fill, and as class after class graduated she sent them far and.wide over the country, to carry the results of their education into hospitals and homes."

[In 1888 Miss Perkins resigned, and her place as superintendent was filled by one of the graduates, Miss Agnes S. Brennan, who still holds the position. To the admirable fidelity of Miss Brennan and her trained intelligence is owing the present efficiency of the school.

A short sketch of the work of the school from 1888 to the present time will appear in another number of the JoukNaI.-ED.]

- Miss Linda Richards was engaged as night superintendent on October 1, 1873, one month after her graduation at the New England Hospital, Boston. 